\title{
Effect of a cordless retraction paste on titanium surface: a topographic, chemical and biocompatibility evaluation
}

Katherine Cooper(a)

Vincent Bennani(a)

Andrew Tawse-Smith ${ }^{(b)}$

Malcolm Reid(c)

Claudine Stirling ${ }^{(c)}$

George Dias ${ }^{(d)}$

\footnotetext{
(a) Department of Oral Rehabilitation, School of Dentistry, Univ of Otago, Dunedin, New Zealand.

(b) Deans Department, School of Dentistry, Univ of Otago, Dunedin, New Zealand.

(c)Department of Chemistry, Centre for Trace Element Analysis, Univ of Otago, Dunedin, New Zealand.

(d) Department of Anatomy, Otago School of Medical Sciences, Univ of Otago, Dunedin, New Zealand.
}

Declaration of Interests: The authors certify that they have no commercial or associative interest that represents a conflict of interest in connection with the manuscript.

Corresponding Author:

Vincent Bennani

E-mail: vincent.bennani@stonebow.otago.ac.nz

Submitted: Nov 14, 2012

Accepted for publication: Feb 22, 2013

Last revision: Mar 13, 2013

\begin{abstract}
Good exposure of the preparation margins and haemostasis in the sulcular gingiva are necessary for accurate impressions to produce precise restorations. The use of cordless retraction paste material in implant dentistry is a relatively novel application. However, few studies have been conducted on the use of retraction pastes and their possible interaction with implant surfaces. Recent literature has described remnants on titanium implant surfaces and expressed the need for an assessment of the biocompatibility of the exposed surface (Chang et al.). This in vitro study evaluated the effect of a cordless gingival retraction paste on sterile titanium disks. Surface chemistry was determined using energy-dispersive X-ray spectroscopy (EDS), and further investigated using laser ablation inductively coupled plasma mass spectrometry (LA-ICP-MS). After exposure to retraction paste, surface chemistry alterations were identified. A fibroblast cell line (L929) was exposed to the disks and the live/ dead viability/cytotoxicity assay was used to determine any effects on the proliferation and health of cells. The disks exposed to the retraction paste showed fewer dead cells compared to the unexposed disks. This was statistically significant.
\end{abstract}

Descriptors: Dental Impression Materials; Dental Impression Technique; Dental Implants.

\section{Introduction}

The use of gingival retraction paste material in implant dentistry appears to have considerable potential. Although some studies have been conducted on this innovative application, there is a need for further investigation into the biocompatibility of the implant surfaces after they have been exposed to a retraction paste material.

Gingival sulcus opening and haemostasis around an abutment is required to obtain an accurate impression of the preparation site. ${ }^{1}$ Most of the time, a gingival retraction cord soaked in an astringent medicament, such as aluminium chloride $\left(\mathrm{AlCl}_{3}\right)$, is used for tissue retraction and haemostasis before impression taking for cement-retained implant restorations. $\mathrm{AlCl}_{3}$ is the least irritating among the chemicals used for gingival retraction and has the longest lasting retraction effect after its removal from the sulcus. Displacing forces exerted on peri-implant tissue during the cord pack- 
ing procedure could cause irreversible trauma. Using an injectable matrix containing $\mathrm{AlCl}_{3}$ as an alternative for gingival retraction is an atraumatic procedure with reduced risk of trauma to peri-implant tissue.,3

The surface of dental implants is a key contributor to successful osseointegration. ${ }^{3}$ For titanium implants, oxidation of its surface results in an excess of free radicals and oxygenated derivatives which form a titanium dioxide layer. In order to make the bone/ implant interface highly dynamic, some ions, such as calcium and phosphorus, also present in bone, are incorporated within this titanium oxide layer. Alteration or damage to the oxide layer leads to a pathological loss of osseointegration called peri-implantitis. ${ }^{4}$ The factors contributing to peri-implantitis fall into four categories:

- lesions of peri-implant attachment,

- presence of aggressive bacterial strains,

- excessive mechanical stress and

- corrosion. $^{3}$

If the implant surface topography and chemistry is altered during the gingival retraction process, implant biocompatibility may be affected.

According to Chang et al. ${ }^{5}$ traces of retraction paste remain on implant surfaces even after two rinses with distilled water. Further research is required to quantify the amount and effect of these remnants on implant surface biocompatibility. Some tests have used cell cultures of fibroblasts or osteoblast-like cells to investigate biocompatibility on a titanium surface. ${ }^{6,7}$ Imaging techniques have been used to analyze cell adhesion, proliferation and differentiation of cells cultured on these surfaces, including scanning electron microscopy. ${ }^{8}$

ISO categories are designed to evaluate the biocompatibility of medical devices used in dentistry ${ }^{9,10}$ by assessing cell damage through morphologic analysis, the measuring of cell growth/proliferation and the investigation of specific aspects of cell metabolism. The most reliable method of assessment is a standardised analysis of cell morphology by a histomorphologist. Culture and quantitative measurement of human diploid fibroblasts are an appropriate model for identifying the early cytotoxic effects of dental materials. ${ }^{11}$
In this in vitro study, we evaluated the effect of a cordless gingival retraction paste on sterile titanium disks. The surface chemistry was first determined using energy-dispersive X-ray spectroscopy (EDS), and further investigated using laser ablation inductively coupled plasma mass spectrometry (LA-ICPMS). Cell cytotoxicity was determined using the live/dead viability/cytotoxicity assay. ${ }^{12}$ The aim of this investigation was to determine whether the application of a gingival retraction paste to a titanium surface alters surface chemistry, and, if so, whether this would have a detrimental effect on cells, hence on biocompatibility.

\section{Methodology}

\section{Disk samples and gingival retraction paste}

Seventy-two $7 \mathrm{~mm} \times 2 \mathrm{~mm}$ thick sterile titanium disks from Southern Implant ${ }^{\circledR}$ (Southern Implant, Irene, South Africa; ASTM-F67-95 Grade 4 pure titanium) were used. The disks had standardised enhanced moderately rough surfaces $\left(S_{a}=1.43 \mathrm{~nm}\right)$ with the same surface topography and chemistry as those of Southern implants. Table 1 demonstrates how the disks were assigned to the different methods.

A gingival retraction paste (Expasy ${ }^{\circledR}$; Acteon, Bordeaux, France) was applied on the surface of the disks using a handgun applicator. Expasyl ${ }^{\circledR}$ (Acteon) is a kaolin-based material with $15 \%$ aluminium chloride.

\section{Exposure protocol}

Half of a cartridge $\left(0.30 \mathrm{~cm}^{3}\right)$ of Expasyl ${ }^{\circledR}$ gingival retraction paste (Acteon) was applied onto the whole surface of each disk for 10 minutes to simulate possible incomplete removal of the paste after rinsing (the manufacturer's recommendation is one to two minutes). To achieve the same pressure generated during placement of Expasyl ${ }^{\circledR}$

Table 1 - Study outline specifying the number of disks used for each test.

\begin{tabular}{c|c|c|c|c}
\hline & SEM & EDS & LA-ICP-MS & Cell culture \\
\hline Control & 1 & 5 & 6 & 24 \\
\hline Exposed & 1 & 5 & 6 & 24 \\
\hline
\end{tabular}


(Acteon) material in vivo (143 $\mathrm{kPa}),{ }^{13}$ a weight of $225 \mathrm{~g}$ was applied to the paste during contact with the disk. Following the protocol established by Chang et al. ${ }^{5}$, each disk was rinsed twice with distilled water and spray set at 50 psi for two minutes. All these procedures were carried out in a sterile environment, with sterile plastic equipment to avoid any contamination of the disks.

\section{Surface topography and chemistry}

A scanning electron microscope (SEM; JEOL 6700 Field Emission SEM, Tokyo, Japan) was used to capture images of the surface before and after application of Expasyl ${ }^{\circledR}$ (Acteon). An accelerating voltage of $15 \mathrm{kV}$ was selected for analysis with the SEM. Local compositional differences across the surface were observed in the backscattered electron mode (BSE).

Survey electron-dispersive spectroscopy (EDS) elemental data were acquired under an accelerating voltage of $25 \mathrm{kV}$. SEM and semi-quantitative EDS analysis was carried out on the disk surfaces before and after contact with the gingival retraction paste.

Furthermore, the composition of $\mathrm{Al}$ and $\mathrm{Si}$ (main components of Expasyl ${ }^{\circledR}$ ) relative to Ti for each sample was determined at the Centre for Trace Element Analysis, University of Otago, using LA-ICP-MS high sensitivity analysis. ${ }^{14}$ Specifically, a quadrupole 7500 cs ICP-MS instrument (Agilent Technologies, Chicago, USA) was coupled to a NewWave UP-213 Nd:YAG deep UV (213 nm) laser ablation system (Electro Scientific Industries, Portland, USA) for the in situ analysis of elemental composition at the micron scale. Ablation was performed under a pure helium atmosphere whilst the laser was operated in continuous mode using a spot size of $50 \mu \mathrm{m}$, a repetition rate of $5 \mathrm{~Hz}$, and a scan rate of $5 \mu \mathrm{m} / \mathrm{s}$ (Figure 1). The ablated aerosol was entrained into the mass spectrometer by an argon carrier gas flow. Immediately after each sample analysis, the instrument was calibrated with NIST (National Institute of Standards and Technology) glass standards (NIST 610 and NIST 612).

Analyses by LA-ICP-MS were carried out on the disk surface before and after exposure to Expasyl ${ }^{\circledR}$ (Acteon). A total of twelve disks (Southern Implant)
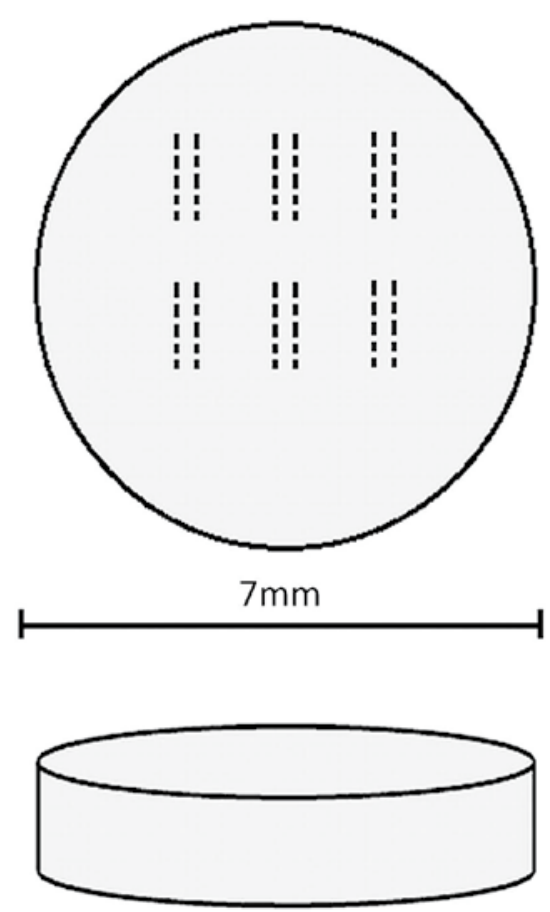

Figure 1 - Schema of the ablation tracks used for LA-ICPMS for each disk.

were analysed (Table 1), followed by instrument calibration. For each disk, laser ablation data were acquired in fixed positions across the surface of the disk as twelve tracks, each $600 \mu \mathrm{m}$ in length. Average $\mathrm{Al} / \mathrm{Ti}$ and $\mathrm{Si} / \mathrm{Ti}$ count ratios were obtained and then scaled according to known ratios for the NIST calibration glasses to derive concentration ratios.

\section{Cell vitality tests}

Viability tests were carried out on a L929 fibroblast cell line. ${ }^{11}$ Disks were seeded at a density of $4 \times 10^{3}$ cells $/ \mathrm{cm}^{2}$, and allowed to adhere for $30 \mathrm{~min}$ utes at $37^{\circ} \mathrm{C}$. Cells were then incubated in $\alpha$-MEM supplemented with $10 \%$ fetal bovine serum (FBS; Invitrogen, Carlsbad, USA) for 48 hours at $37^{\circ} \mathrm{C}$. The media contained L-glutamine, and no antibiotics were used. Cells were grown in $5 \% \mathrm{CO}_{2}$ in a humidified cell culture incubator (Galaxy mini $\mathrm{CO}_{2}$ incubator; New Brunswick Scientific, Enfield, USA).

The relative numbers of live and dead cells were measured using the live/dead viability/cytotoxicity assay. $^{12}$

A confocal microscope was used to detect the 

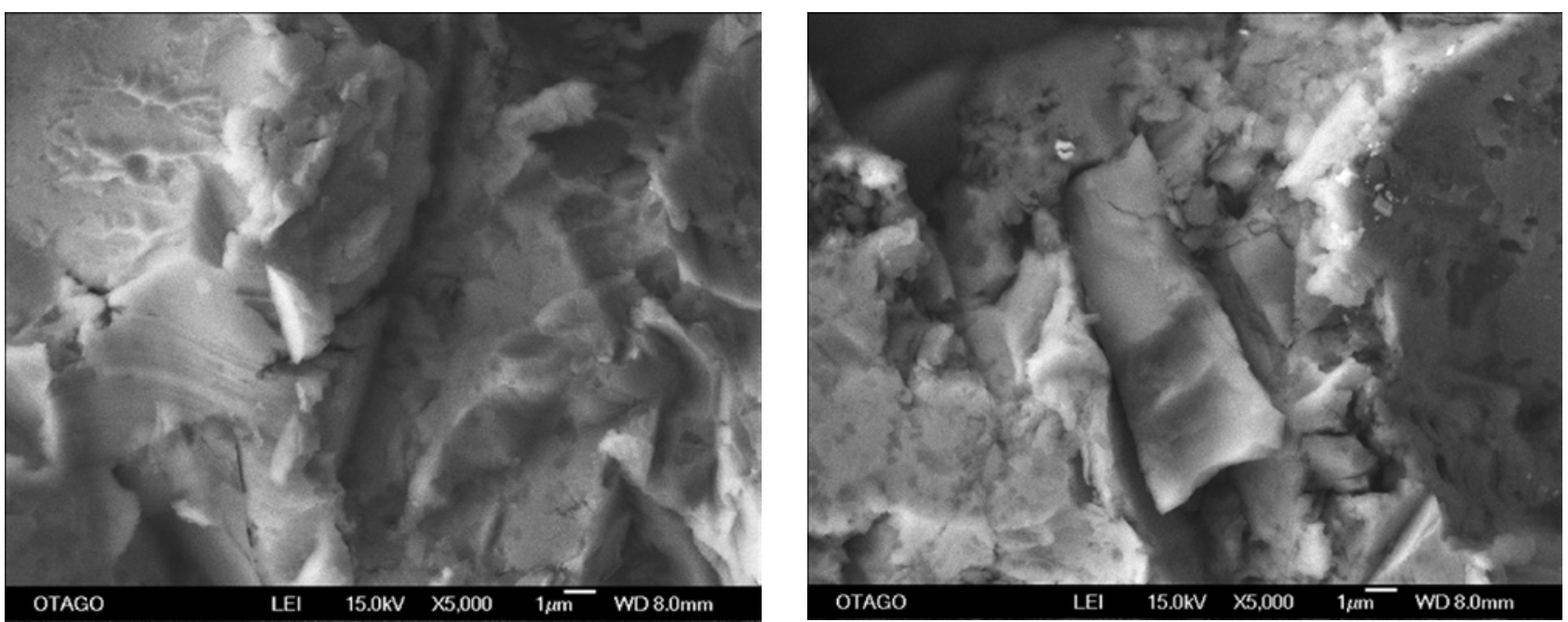

Figure 2 - SEM image at $\times 5000$ magnification of the unpolished disk surface, control (left) and exposed (right). BSE shows deposits of retraction paste on the surface of the exposed disk.

wavelengths produced in the assay. Three images were taken randomly per disk by the same operator, and quantitative analysis of the images was carried out using ImageJ software (Version 1.45S, National Institutes of Health, Baltimore, USA). The colour channels for each image were split, and the green and red considered separately. The threshold for each image was set to 90-255 and the area fitting that intensity was measured with ImageJ software.

\section{Statistical analysis}

The data obtained from each disk was analysed making an educated assumption of a normal distribution pattern. The exposure of disks was the assigned variable for comparison. The student t-test was used for the chemical data. $\mathrm{p}<0.05$ was considered statistically significant. A non-parametric Wilcoxon $\mathrm{T}$ test was used for the biocompatibility data.

\section{Results}

\section{Surface topography using SEM}

Under low magnification $(\times 500)$, no difference in surface topography could be seen between exposed and control disks. The surface was rough with sharp, defined valleys and tops, and variable flank length. At higher magnification $(\times 5000)$, minute particles were visible, particularly in the back-scatter electron (BSE) detector view (Figure 2). These particles measured $0.7 \mu \mathrm{m}$ at most.
Table 2 - EDS results for control and exposed disks.

\begin{tabular}{|c|c|c|c|c|c|c|c|c|c|c|c|c|}
\hline & \multicolumn{3}{|c|}{$C^{*}$} & \multicolumn{3}{|c|}{$\mathrm{Al}_{2} \mathrm{O}_{3}{ }^{*} / * *$} & \multicolumn{3}{|c|}{$\mathrm{SiO}_{2}{ }^{*}$} & \multicolumn{3}{|c|}{$\mathrm{TiO}_{2}{ }^{* *}$} \\
\hline \multirow{2}{*}{ Control } & 2 & 2 & $t$ & 26 & 25 & 23 & $\dagger$ & 0 & 0 & 72 & 71 & 74 \\
\hline & 1 & 1 & 1 & 30 & 24 & 22 & 0 & 0 & 0 & 67 & 74 & 75 \\
\hline \multirow{3}{*}{ Exposed } & 1 & 3 & 2 & 27 & 25 & 21 & $t$ & 2 & 3 & 71 & 71 & 74 \\
\hline & 1 & 1 & 1 & 22 & 19 & 20 & 1 & $t$ & $t$ & 74 & 79 & 77 \\
\hline & & & & \multicolumn{3}{|c|}{$p>0.05$} & \multicolumn{3}{|c|}{$p<0.05$} & & & \\
\hline
\end{tabular}

*Elements originating From Expasy ${ }^{\circledR}$ (Acteon, Bordeaux, France); ${ }^{* *}$ elements originating from the Southern-Implants ${ }^{\circledR}$ disk (Southern Implant, Irene, South Africa); The " $\mathrm{t}$ " stands for trace (below 1\%).

\section{Surface chemistry}

EDS results showed that traces (less than 1\%) of oxygen and silicon were present on the disks exposed to Expasyl ${ }^{\circledR}$ (Acteon). The silicon component in the exposed and control groups was significantly different. Both the exposed and control disks (Southern Implant) were similar with regard to aluminium and titanium, in that both of these elements yielded the highest readings among the elements considered (Table 2).

LA-ICP-MS was carried out to quantify the trace amount of silicon and aluminium detected with EDS (Figure 3). The results showed a statistically significant difference in the ratio of $\mathrm{Si} / \mathrm{Ti}$ between control and exposed disks, in that this ratio was higher in the exposed samples. In contrast, higher amounts of aluminium were detected in the control samples, but this difference was not statistically significant (Table 3). 
Figure 3 - EDS of exposed implant surface.

\section{Cell vitality tests}

The area, thus number, of live cells (those which take up calcein) was greater in the exposed group than in the control group (Figure 4). The area of dead cells was higher in the control disks than in those exposed to Expasyl ${ }^{\circledR}$ (Acteon). The remaining percentage corresponded to black space, or to areas where the florescence was less than 90, thus did not fit the threshold parameters (Table 4).

\section{Discussion}

Packing a gingival retraction cord is the usual method applied in implantodontics and fixed prosthodontics. ${ }^{1}$ The Expasyl ${ }^{\circledR}$ retraction paste (Acteon) provides adequate gingival crevicular opening to achieve an accurate impression of the finishing margins in fixed prosthodontics.

Minimal alterations to surface morphology after contact with Expasyl ${ }^{\circledR}$ (Acteon) were observed in SEM images, which partially supports the findings by Chang et al. ${ }^{5}$ The only change was observed at $\times 5000$ magnification, where "white" particles were visible on the surface. However, this was not replicated in all images of the exposed disks (Southern Implant). The particles could be residual Expasyl ${ }^{\circledR}$ (Acteon) material on the surface, as the EDS results
Table 3 - LA-ICP-MS results, for control and exposed disks, as a ratio relative to titanium.

\begin{tabular}{c|c|c|c}
\hline & Ratio & $\mathrm{Si} / \mathrm{Ti}$ & $\mathrm{Al} / \mathrm{Ti}$ \\
\hline \multirow{3}{*}{ Control } & Mean (SD) & $1.75 \times 10^{-05}(0.02)$ & $9.12 \times 10^{-05}(1.85)$ \\
\cline { 2 - 4 } & Max & $5.10 \times 10^{-05}$ & $1.60 \times 10^{-04}$ \\
\cline { 2 - 4 } & Min & $8.32 \times 10^{-06}$ & $6.10 \times 10^{-05}$ \\
\hline \multirow{3}{*}{ Exposed } & Mean (SD) & $2.60 \times 10^{-05}(0.06)$ & $8.90 \times 10^{-05}(7.41)$ \\
\cline { 2 - 4 } & Max & $5.98 \times 10^{-05}$ & $1.90 \times 10^{-04}$ \\
\cline { 2 - 4 } & Min & $9.30 \times 10^{-06}$ & $4.71 \times 10^{-05}$ \\
\hline
\end{tabular}

$\mathrm{Si} / \mathrm{Ti}, \mathrm{p}<0.05$

showed a statistically significant difference in the silicon component (Table 2). The occasional appearance of white particles would explain the increased variability in the hi-spatial resolution LA-ICP-MS signals, even if not evident on a low spatial resolution technique like EDS. This observation could explain why $\mathrm{Al} / \mathrm{Ti}$ signals were more variable in the exposed counts compared to those of the control.

After exposure to Expasyl ${ }^{\circledR}$ (Acteon), EDS measurements indicated that silicon was present, but only at levels near the instrumental detection limit, an observation consistent with the findings of Chang et al. ${ }^{5}$ Because the EDS silicon data was only con- 

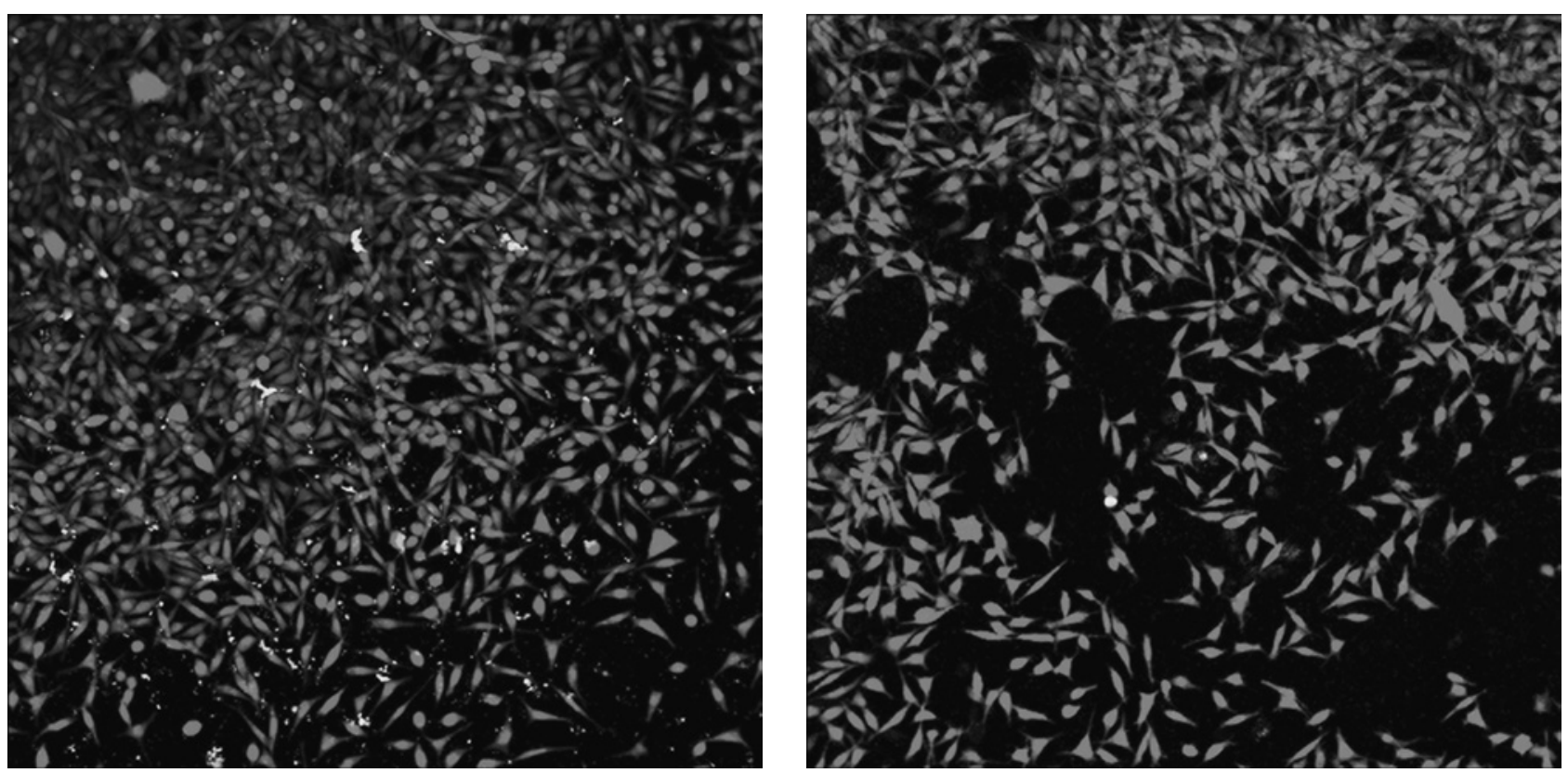

Figure 4 - Confocal images of live/dead viability tests. The control surface (left) shows more red dots than the exposed disk (right). The black spaces represent areas that are not occupied by cells; they are less abundant in the exposed disk (right).

Table 4 - Mean area of all images taken with respect to green and red channels.

\begin{tabular}{l|r|r|r}
\hline & Control & Exposed & \\
\hline Green & $17.54 \%$ & $24.47 \%$ & \\
\hline Red & $0.87 \%$ & $0.33 \%$ & $\mathrm{p}<0.05$ \\
\hline Black & $81.60 \%$ & $75.21 \%$ & \\
\hline $\begin{array}{l}\text { Total \% surface with cells } \\
\text { present (area not black) }\end{array}$ & $18.41 \%$ & $24.80 \%$ & \\
\hline Green & $95.32 \%$ & $98 \%$ & \\
\hline
\end{tabular}

sidered to be indicative, LA-ICP-MS was employed to fully quantify elemental abundances owing to its sensitivity and spatial resolution. ${ }^{14}$

The EDS showed that titanium and some aluminium were present before the disk (Southern Implant) was exposed. Titanium was present because the disk was grade 4 titanium. The presence of aluminium was accounted for by its addition used to modify the surface to enhance osseointegration. ${ }^{3,5}$ LA-ICPMS analysis of the disks showed a predominance of titanium and aluminium counts before treatment with Expasy ${ }^{\circledR}$ (Acteon). Aluminium, which is present in both the unexposed disk surfaces and in the Expasyl ${ }^{\circledR}$ paste (Acteon), varied within and between sample groups (exposed and control). The variation in the control disks meant that a baseline for aluminium could not be accurately determined. Hence, the anticipated increase after exposure could not be accurately measured.

One limitation of the LA-ICP-MS method is that the depth of ablation is difficult to control. Further research on this aspect is needed.

The cell viability assay results indicated that there was a difference in biocompatibility between the surfaces. L929 cells are well characterised and widely used in research. They have a high proliferation rate, and are relatively resilient. Experimentally, the cells were reaching $80 \%$ confluence at 48 hours when initially seeded with $2 \times 10^{3}$ cells/well in 24-well plates. This was calculated using an ATCC L929 data sheet protocol, and is an appropriate number for analysis and to ensure healthy cells.

When seeding the cells, it was noticed that the cells spread better on the exposed disks as compared to the control disk. This could imply an increased biocompatibility. The results showed less than $2 \%$ dead cells in both disk groups. The exposed disks achieved higher areas of live cells $198 \%$ in the exposed versus $95.32 \%$ in the control). It is possible that an increased wettability of the surface caused the slight difference in cell viability. This difference 
was not statistically significant, therefore with negligible clinical implications; however, it could be an area for further research.

Furthermore, the aforementioned result was complemented by analysing the black area in the images. This area reflects the area not covered with live or dying cells, and was lower in the exposed disk group.

Another finding that could support this statement is that, when using the proteolysis enzyme trypsin to detach cells during the 3-(4,5-dimethylthiazol-2yl)-5-(3-carboxymethoxyphenyl)-2-(4-sulfophenyl)2H-tetrazolium (MTS) assay (as described in ISO$10993)^{10}$ to determine cell viability, the cells would not detach from the exposed disk surface. Only after applying trypsin for twice the amount of time recommended (10 minutes) did the cells detach, which is detrimental to the cells. Thus, the live/dead viability cytotoxicity test, that does not require cell detachment, was used.

\section{References}

1. Shannon A. Expanded clinical uses of a novel tissue retraction material. Compend Contin Educ Dent. 2002 Jan;23(1Suppl):3-6.

2. Bennani V, Schwass D, Chandler N. Gingival retraction techniques for implants versus teeth. J Am Dent Assoc. 2008 Oct;139(10):1354-63.

3. Dohan Ehrenfest DM, Coelho PG, Kang B-S, Sul Y-T, Albrektsson T. Classification of osseointegrated implant surfaces: materials, chemistry and topography. Trends Biotechnol. 2010 Apr; 28(4):198-206.

4. Mouhyi J, Ehrenfest DD, Albrektsson T. The peri-implantitis: implant surfaces, microstructure and physicochemical aspects. Clin Implant Dent Relat Res. 2012 Apr;14(2):170-83.

5. Chang Y-S, Bennani V, Tawse-Smith A, Girvan L. Effect of a cordless retraction paste material on implant surfaces: an in vitro study. Braz Oral Res. 2011 Nov-Dec;25 (6):492-9.

6. Groessner-Schreiber B, Neubert A, Muller A-D, Hopp M, Griepentrog M, Lange K-P. Fibroblast growth on surfacemodified dental implants: an in vitro study. J Biomed Mater Res. 2003;64:591-9.

7. Pae A, Kim S, Kim H, Woo Y. Osteoblast-like cell attachment and proliferation on turned, blasted and anodized titanium surfaces. Int J Oral Maxillofac Implants. 2011 MayJun;26(3):475-81.

8. Mustafa K, Wennerberg A, Wroblewski J, Hultenby K, Lopez B, Arvidson K. Determining optimal surface roughness

\section{Conclusion}

1. Chemical analysis indicated the presence of silicon after application of Expasyl ${ }^{\circledR}$ (Acteon).

2. Exposing the titanium disks to Expasyl ${ }^{\circledR}$ (Acteon) did not affect their viability.

\section{Acknowledgements}

The authors thank Pierre-Roland, a division of the Acteon Group (Bordeaux, France), for providing financial support for this research, and appreciate the use of the testing facilities at the University of Otago, New Zealand, and the Sir John Walsh Research Institute for their support. The authors also wish to thank Professor Peter Herbison, for his assistance with the statistical analysis; Keppel Kooman, for his help with the cell culture, and Liz Girvan, for the SEM work involved in this study. Claudine Stirling and Malcom Reid gratefully acknowledge the Community Trust of Otago for initial financial support to the Centre for Trace Element Analysis.

of aTiO2 blasted titanium implant material for attachment, proliferation and differentiation of cells derived from human mandibular alveolar bone. Clin Oral Implant Res. 2001 Oct;12(6):515-25.

9. International Organization for Standardization. ISO-7405: dentistry - evaluation of biocompatibility of medical devices used in dentistry. Geneva: ISO; 2008. 7 p.

10. International Organization for Standardization. ISO-10993-5: biological evaluation of medical devices - part 5: tests for in vitro cytotoxicity. Geneve: ISO; 2009. 34 p.

11. Willerhausen B, Marroquin B, Schaefer D, Schulze R. Cytotoxicity of root canal filling materials to three different human cell lines. J Endo. 2000 Dec;26(12):703-7.

12. Viability/Cytotoxicity Kit for mammalian cells. Molecular Probes. Invitrogen Detection technologies.Eugene: Product information; $2005.7 \mathrm{p}$.

13. Bennani V, Aarts J, He L. A comparison of the pressure generated by cordless gingival displacement techniques. J Prosthe Dent. 2012 Jun;107(6):388-92.

14. Heirich C, Pettke T, Halter W, Aigner-Torres M, Audetat A, Gunther D, et al. Quantitative multi-element analysis of minerals, fluid and melt inclusions by laser-ablation inductivelycoupled-plasma mass-spectrometry. Geochim Cosmochim Acta. 2003;67(18):3473-97. 